\title{
A review of invasive lobular carcinoma of the breast: Should it be treated like invasive ductal carcinoma?
}

\author{
Lee Joycelyn Jie Xin and Lee Guek Eng* \\ Department of Medical Oncology, National Cancer Centre Singapore, Singapore
}

\begin{abstract}
In this article, we review the evidence detailing the clinical, pathological and genomic differences between invasive lobular carcinoma (ILC) and invasive ductal carcinoma (IDC) of the breast. Even within ILC, there is great variation within its subtypes. Although current guidelines suggest that ILC and IDC should be managed similarly, future trials should stratify by histological subtype and more research needs to be done to elucidate molecular characteristics, so as to better tailor and optimise treatment for patients.
\end{abstract}

\section{Introduction}

There is increasing evidence that invasive lobular carcinoma (ILC) differs from invasive ductal carcinoma (IDC), in their clinical, pathological and genomic characteristics, yet current guidelines suggest that they be managed similarly, against many physician's opinions [1]. Even within ILC, there is great variation within different histological subtypes. We aim to provide a concise review of the peculiarities of breast ILC.

\section{Epidemiology and pathogenesis}

ILC is the second most common breast cancer subtype [2] accounting for about $10 \%$ of breast cancer cases. Even within ILC, there are more than ten histopathologic variants [3], including the classical subtype (56\%), the alveolar variant (15\%), the solid subtype (11\%), the mixed non-classic variant and the pleormorphic variant. Most ILC are hormone receptor- positive and HER2 receptor negative [4], with up to $95 \%$ being estrogen receptor (ER) positive, and $70 \%$ being progesterone receptor (PR) positive. They most often belong to the luminal molecular subtype [5] with most not expressing HER2 nor basal epithelial markers. The pleomorphic variant of ILC however shows a relatively higher frequency of HER2 expression of up to 35 $80 \%$ and is more often ER-negative or triple negative [6], with only $10-76 \%$ of pleomorphic ILC being ER-positive. Correspondingly, the proliferation index is typically higher and the tumour displays a more aggressive clinical course $[7,8]$.

Since ILC is commonly strongly ER- and PR-positive, it is expected that traditional hormone-related risk factors causing increased estrogen exposure will also be applicable. Several observational studies suggest that the relative risk of breast cancer for a post-menopausal woman on combined hormonal replacement therapy was higher for that of ILC than for IDC $[9,10]$, with the relative risk of 1.5 for IDC compared to more than 2.0 for ILC [11]. There was less of such a differential risk by histological subtype for the use of estrogen hormonal therapy however, with a relative risk of 1.1 for IDC and 1.4 for ILC. Similar findings were reported for other traditional hormone-related risk factors such as early menarche, later age of menopause [12] and later age at first birth $[13,14]$, with stronger associations shown between the risk factor for ILC than for IDC. To the best of our knowledge, there is no current published data on the different risk of oral contraceptives on different histological subtypes of breast cancer [11]. Among other lifestyle factors, alcohol consumption of seven of more alcoholic beverages also conferred a higher risk for ILC than for IDC among post-menopausal women $[15,16]$.

Of the four high penetrance genes with known genetic susceptibility to breast cancer, BRCA1 and TP53 are predominantly associated with IDC, BRCA2 mutations are associated with both ductal and lobular subtypes while $C D H 1$ mutations are exclusively associated with ILC breast cancers [11]. The frequency of ILC breast cancers in BRCA2 mutation carriers is around $8.4 \%$, similar to that in the general population, while ILC is grossly underrepresented in proportion among BRCA1 mutation carriers [17].

Familial clustering of ILC has also been reported. Some of these cases are associated with germline mutations in the $C D H 1$ gene on chromosome 16q. The $\mathrm{CDH} 1$ gene codes for the E-cadherin protein, which plays a role in cell adhesion [18]. Germline inactivation in this tumour suppressor gene has also been associated with diffuse gastric cancer (DGC). Loss of E-cadherin is thought to be oncogenic both loss of cellular cohesion, as well as by triggering secondary changes such as the loss of beta-catenin and aberrant cellular location of p120-catenin; leading to promotion of cancer cell motility, migration and invasion $[19,20]$. Even in the absence of inherited germline mutations in $C D H 1$, the loss of E-cadherin expression is almost a universal occurrence in ILC $[21,22]$, largely due to somatic $C D H 1$ frameshift mutations and loss of heterozygosity or aberrant $C D H 1$ promoter methylation [23]. On the contrary, E-cadherin expression is almost always intact in IDC [24]. Other genetic abnormalities commonly implicated include mutations of the PIK3CA/AKT/PTEN [25] and FOXA1 genes [26] and ESR1 copy number gains [27], while mutations of TP53 and GATA3 are rare unlike in IDC, with the exception of the pleomorphic variant of ILC.

Correspondence to: Lee Guek Eng, Department of Medical Oncology, National Cancer Centre Singapore, 11 Hospital Drive, Singapore 169610, E-mail: lee.guek.eng@singhealth.com.sg

Received: October 12, 2016; Accepted: October 26, 2016; Published: October 29, 2016 


\section{Imaging}

The mammographic detection of ILC is more difficult that of IDC due to its diffuse infiltrative pattern of growth with indistinct margins, causing mammographic to be less sensitive for its detection [28]. Rather than a discrete well-circumscribed mass with a central opacity, the typical mammographic finding for ILC is a spiculated, poorlydefined mass with asymmetrical densities [29] or simply, architectural distortion. Calcifications are also a rarely seen mammographic finding in ILC [30]. Sensitivity of mammogram for ILC hence is reported to be around $57-81 \%$ [29], lower than that for IDC, with up to a third of ILC tumours being missed [31].

As such, other modes of imaging are frequently used to complement that of mammography, with both ultrasound [32] and magnetic resonance imaging (MRI) [33] showing higher sensitivities for ILC detection. On ultrasound, similar to mammography, ILC is rarely seen as a well-circumscribed mass and even up to $20 \%$ of cases may lack typical sonographic features of posterior acoustic shadowing. More than $10 \%$ of ILC may be undetected with ultrasound, with a sensitivity of $68-98 \%$ [32,34,35], higher than that of mammography, even when taking into account that some of these studies used older sonographic techniques. More importantly, $73 \%$ of ILC tumours that could not be detected by mammography could be identified by ultrasound and $92 \%$ of ILC tumours with only subtle findings on mammography were confirmed by ultrasound [32]; reinforcing the usefulness of sonography as an adjunct to mammography in ILC diagnosis.

Breast MRI has a higher sensitivity of $93 \%$ for detection ILC but also comes at a tradeoff of reduced specificity [33].

In addition to its use as screening in women with a high lifetime risk of breast cancer [36], MRI has also been studied in a role for preoperative imaging and planning. In the latter, though routine use is still controversial, in some studies it has been shown to influence surgical management in about a quarter of cases when used for preoperative planning [37], with lower rates of re-excision with better definition of disease extent upfront.

Promising techniques such as breast specific gamma imaging (BSGI) [38] and tomosynthesis [39,40] are currently being studied as imaging adjuncts to conventional methods for ILC. BSGI, or molecular breast imaging (BMI) has the highest sensitivity among all the imaging modalities for breast cancer, and also for ILC, at $93 \%$. It however requires exposure to higher radiation doses, but still is a promising adjunct modality [38]. Breast tomosynthesis is a low-dose mammogram technique with greater ability in detecting architectural distortion [40], a common imaging feature of ILC. When combined with digital mammography, it has been shown to increase the detection rate of ILC compared to the latter modality alone [39].

\section{Treatment and prognosis}

Although breast conservation surgery (BCS) is a viable option for ILC [41], there is an increased incidence of positive resection margins as compared to patients who underwent BCS for IDC [42], resulting in a need for a second operation to ensure complete excision. Mastectomy is more often performed in ILC with one series reporting mastectomy rates of $57 \%$ in ILC patients compared to $46 \%$ in IDC [43]. This may be due to the larger size of ILC tumours as well as their multifocality.

The response rates of ILC tumours to neoadjuvant chemotherapy are lower than that of IDC with $41 \%$ of ILCs being downstaged compared to similar downstaging in $64 \%$ of IDCs in one series [44].
In the same series, pathological complete response ( $\mathrm{pCR}$ ) rates were also lower in ILC at 3.5\% compared to IDC at 14\%, though histological subtype alone was not a statistically significant factor [44], and instead, this has been postulated to be related to their low grade and proliferative rates [45]. The magnitude of benefit from trastuzumab however is similar for both ILC and IDC [46].

Even though ILC responds poorly to neoadjuvant chemotherapy, it has been shown to respond well to endocrine therapy [47]. However, the magnitude of benefit differs with different endocrine therapy. There is also preclinical data that tamoxifen is not an ideal endocrine therapy in ILC patients, with ILC tumour models showing a paradoxical induction of cellular proliferation in response to the drug, suggesting that the estrogen receptor may have different isoforms $[48,49]$, or drive different signaling pathways in the two histological subtypes [50,51]. Differential ER activity between the IDC and ILC has also been suggested at a gene expression level [26]. Clinically, this has also been observed in several retrospective analyses showing that post-menopausal patients with ILC derive more a greater magnitude of benefit from aromatase inhibitors than do patients with IDC [52,53]. Analysis of patients in the Breast International Group (BIG) 1-98 trial showed that letrozole was associated with a $50-66 \%$ reduction in DFS event risk in ILC patients compared to a $0-35 \%$ risk reduction in patients with IDC [52]. This difference may however possibly be ameliorated by a switch from tamoxifen to an aromatase inhibitor [54].

Although short term disease free survival is often better in ILC [55], higher rates of late recurrences have been documented and longterm overall survival rates do not differ significantly between the two subtypes [56,57] or may even be worse for ILC [58]. Up to $30 \%$ of patients developing subsequent metastatic disease [59]. The pattern of metastases from ILC also shows an interesting distribution, with more gastrointestinal [60] and peritoneal or ovarian metastases [61], and less lung metastases compared to their IDC counterparts [60]. Gastric metastases seem to be particularly common, and should be differentiated from a primary gastric tumour [62], especially in view that both ILC and diffuse gastric cancers can occur together in the hereditary diffuse gastric cancer (HDGC) syndrome [63].

\section{Conclusion}

ILC differs greatly from IDC in many important ways. From sensitivity of imaging techniques in their detection, to pathological and molecular characteristics, these two subtypes have significant differences that contribute to their different clinical course, responses to treatment and prognosis. Even within ILC, there is great heterogeneity. Current guideline recommendations that both histological subtypes should be managed similarly stems more from insufficient knowledge and data rather than a true belief that the two subtypes should be managed identically.

Future trials should stratify recruitment by histological subtype and more studies are needed to evaluate the molecular characteristics of ILC. This will allow us to better understand the disease biology of ILC better and help us better tailor treatment choices for patients.

\section{References}

1. Jacobs C, Ibrahim MF, Clemons M, Hutton B, Simos D, et al. (2015) Treatment choices for patients with invasive lobular breast cancer: a doctor survey. J Eval Clin Pract 21: 740-748. [Crossref]

2. Li CI, Daling JR (2007) Changes in breast cancer incidence rates in the United States by histologic subtype and race/ethnicity, 1995 to 2004. Cancer Epidemiol Biomarkers Prev 16: 2773-2780. [Crossref] 
3. Iorfida M, Maiorano E, Orvieto E, Maisonneuve P, Bottiglieri L, et al. (2012) Invasive lobular breast cancer: subtypes and outcome. Breast Cancer Res Treat 133: 713-723. [Crossref]

4. Arpino G, Bardou VJ, Clark GM, Elledge RM (2004) Infiltrating lobular carcinoma of the breast: tumor characteristics and clinical outcome. Breast Cancer Res 6: R149-156. [Crossref]

5. Bertucci F, Orsetti B, Nègre V, Finetti P, Rougé C, et al. (2008) Lobular and ductal carcinomas of the breast have distinct genomic and expression profiles. Oncogene 27: 5359-5372. [Crossref]

6. Ohashi R, Matsubara M, Watarai Y, Yanagihara K, Yamashita K, et al. (2016) Pleomorphic lobular carcinoma of the breast: a comparison of cytopathological features with other lobular carcinoma variants. Cytopathology. [Crossref]

7. Ercan C, van Diest PJ, van der Ende B, Hinrichs J, Bult P, et al. (2012) p53 mutations in classic and pleomorphic invasive lobular carcinoma of the breast. Cell Oncol (Dordr) 35: 111-118. [Crossref]

8. Buchanan CL, Flynn LW, Murray MP, Darvishian F, Cranor ML, et al. (2008) Is pleomorphic lobular carcinoma really a distinct clinical entity? J Surg Oncol 98: 314317. [Crossref]

9. Flesch-Janys D, Slanger T, Mutschelknauss E, Kropp S, Obi N, et al. (2008) Risk of different histological types of postmenopausal breast cancer by type and regimen of menopausal hormone therapy. Int J Cancer 123: 933-941. [Crossref]

10. Fournier A, Fabre A, Mesrine S, Boutron-Ruault MC, Berrino F, et al. (2008) Use of different postmenopausal hormone therapies and risk of histology- and hormone receptor-defined invasive breast cancer. J Clin Oncol 26: 1260-1268. [Crossref]

11. Dossus L, Benusiglio PR (2015) Lobular breast cancer: incidence and genetic and nongenetic risk factors. Breast Cancer Res 17: 37. [Crossref]

12. Collaborative Group on Hormonal Factors in Breast Cancer (2012) Menarche, menopause, and breast cancer risk: individual participant meta-analysis, including 118 964 women with breast cancer from 117 epidemiological studies. Lancet Oncol 13: 1141-1151. [Crossref]

13. Rosenberg LU, Magnusson C, Lindström E, Wedrén S, Hall P, et al. (2006) Menopausal hormone therapy and other breast cancer risk factors in relation to the risk of different histological subtypes of breast cancer: a case-control study. Breast Cancer Res 8: R11. [Crossref]

14. Kotsopoulos J, Chen WY, Gates MA, Tworoger SS, Hankinson SE, et al. (2010) Risk factors for ductal and lobular breast cancer: results from the nurses' health study. Breast Cancer Res 12: R106. [Crossref]

15. Li CI, Chlebowski RT, Freiberg M, Johnson KC, Kuller L, et al. (2010) Alcohol consumption and risk of postmenopausal breast cancer by subtype: the women's health initiative observational study. J Natl Cancer Inst 102: 1422-1431. [Crossref]

16. Li CI, Daling JR, Malone KE, Bernstein L, Marchbanks PA, et al. (2006) Relationship between established breast cancer risk factors and risk of seven different histologic types of invasive breast cancer. Cancer Epidemiol Biomarkers Prev 15: 946-954. [Crossref]

17. Mavaddat N, Barrowdale D, Andrulis IL, Domchek SM, Eccles D, et al. (2012) Pathology of breast and ovarian cancers among BRCA1 and BRCA2 mutation carriers: results from the Consortium of Investigators of Modifiers of BRCA1/2 (CIMBA). Cancer Epidemiol Biomarkers Prev 21: 134-147. [Crossref]

18. Niessen CM, Gottardi CJ (2008) Molecular components of the adherens junction. Biochim Biophys Acta 1778: 562-571. [Crossref]

19. Sarrió D, Pérez-Mies B, Hardisson D, Moreno-Bueno G, Suárez A, et al. (2004) Cytoplasmic localization of p120ctn and E-cadherin loss characterize lobular breas carcinoma from preinvasive to metastatic lesions. Oncogene 23: 3272-3283. [Crossref]

20. Schackmann RC, van Amersfoort M, Haarhuis JH, Vlug EJ, Halim VA, et al. (2011) Cytosolic p120-catenin regulates growth of metastatic lobular carcinoma through Rock1-mediated anoikis resistance. J Clin Invest 121: 3176-3188. [Crossref]

21. Rakha EA, Patel A, Powe DG, Benhasouna A, Green AR, et al. (2010) Clinical and biological significance of E-cadherin protein expression in invasive lobular carcinoma of the breast. Am J Surg Pathol 34: 1472-1479. [Crossref]

22. Moll R, Mitze M, Frixen UH, Birchmeier W (1993) Differential loss of E-cadherin expression in infiltrating ductal and lobular breast carcinomas. Am J Pathol 143: 17311742. [Crossref]

23. Droufakou S, Deshmane V, Roylance R, Hanby A, Tomlinson I, et al. (2001) Multiple ways of silencing E-cadherin gene expression in lobular carcinoma of the breast. Int $J$
Cancer 92: 404-408. [Crossref]

24. Rakha, EA, Teoh TK, Lee AH, Nolan CC, Ellis IO, et al. (2013) Further evidence that E-cadherin is not a tumour suppressor gene in invasive ductal carcinoma of the breast: an immunohistochemical study. Histopathology 62: 695-701. [Crossref]

25. Christgen M, Noskowicz M, Schipper E, Christgen H, Heil C, et al. (2013) Oncogenic PIK3CA mutations in lobular breast cancer progression. Genes Chromosomes Cancer 52: 69-80. [Crossref]

26. Ciriello G, Gatza ML, Beck AH, Wilkerson MD, Rhie SK, et al. (2015) Comprehensive Molecular Portraits of Invasive Lobular Breast Cancer. Cell 163: 506-519. [Crossref]

27. Desmedt C, Zoppoli G, Gundem G, Pruneri G, Larsimont D, et al. (2016) Genomic Characterization of Primary Invasive Lobular Breast Cancer. J Clin Oncol 34: 1872 1881. [Crossref]

28. Kolb TM, Lichy J, Newhouse JH (2002) Comparison of the performance of screening mammography, physical examination, and breast US and evaluation of factors that influence them: an analysis of 27,825 patient evaluations. Radiology 225: 165-175. [Crossref]

29. Johnson K, Sarma D1, Hwang ES2 (2015) Lobular breast cancer series: imaging. Breast Cancer Res 17: 94. [Crossref]

30. Mendelson EB, Harris KM, Doshi N, Tobon H (1989) Infiltrating lobular carcinoma: mammographic patterns with pathologic correlation. AJR Am J Roentgenol 153: 265 271. [Crossref]

31. Porter AJ, Evans EB, Foxcroft LM, Simpson PT, Lakhani SR (2014) Mammographic and ultrasound features of invasive lobular carcinoma of the breast. $J$ Med Imaging Radiat Oncol 58: 1-10. [Crossref]

32. Butler RS, Venta LA, Wiley EL, Ellis RL, Dempsey PJ, et al. (1999) Sonographic evaluation of infiltrating lobular carcinoma. AJR Am J Roentgenol 172: 325-330. [Crossref]

33. Mann, R.M., et al., (2008) MRI compared to conventional diagnostic work-up in the detection and evaluation of invasive lobular carcinoma of the breast: a review of existing literature. Breast Cancer Res Treat 107: 1-14. [Crossref]

34. Paramagul CP, Helvie MA, Adler DD (1995) Invasive lobular carcinoma: sonographic appearance and role of sonography in improving diagnostic sensitivity. Radiology 195 231-234. [Crossref]

35. Selinko VL, Middleton LP, Dempsey PJ (2004) Role of sonography in diagnosing and staging invasive lobular carcinoma. J Clin Ultrasound 32: 323-332. [Crossref]

36. Lehman CD, DeMartini W, Anderson BO, Edge SB (2009) Indications for breast MRI in the patient with newly diagnosed breast cancer. J Natl Compr Canc Netw 7: 193-201. [Crossref]

37. Mann RM, Loo CE, Wobbes T, Bult P, Barentsz JO, et al. (2010) The impact of preoperative breast MRI on the re-excision rate in invasive lobular carcinoma of the breast. Breast Cancer Res Treat 119: 415-422. [Crossref]

38. Brem RF, Ioffe M, Rapelyea JA, Yost KG, Weigert JM, et al. (2009) Invasive lobular carcinoma: detection with mammography, sonography, MRI, and breast-specific gamma imaging. AJR Am J Roentgenol 192: 379-383. [Crossref]

39. Friedewald SM, Rafferty EA, Rose SL, Durand MA, Plecha DM, et al. (2014) Breast cancer screening using tomosynthesis in combination with digital mammography. JAMA 311: 2499-2507. [Crossref]

40. Partyka, L, Lourenco AP, Mainiero MB (2014) Detection of mammographically occult architectural distortion on digital breast tomosynthesis screening: initial clinical experience. AJR Am J Roentgenol 203: 216-222. [Crossref]

41. Sharma SD, Barry M, O'Reilly EA, Kell MR (2015) Surgical management of lobular carcinoma from a national screening program: a retrospective analysis. Eur J Surg Oncol 41: 79-85. [Crossref]

42. Biglia N, Maggiorotto F, Liberale V, Bounous VE, Sgro LG, et al. (2013) Clinicalpathologic features, long term-outcome and surgical treatment in a large series of patients with invasive lobular carcinoma (ILC) and invasive ductal carcinoma (IDC). Eur J Surg Oncol 39: 455-460. [Crossref]

43. Truin W1, Roumen RM, Siesling S, van der Heiden-van der Loo M, Duijm LE, et al (2015) Patients with invasive lobular breast cancer are less likely to undergo breastconserving surgery: a population based study in the Netherlands. Ann Surg Oncol 22: 1471-1478. [Crossref]

44. Delpech Y, Coutant C, Hsu L, Barranger E, Iwamoto T, et al. (2013) Clinical benefit from neoadjuvant chemotherapy in oestrogen receptor-positive invasive ductal and lobular carcinomas. Br J Cancer 108: 285-291. [Crossref] 
45. Mathieu MC, Rouzier R, Llombart-Cussac A, Sideris L, Koscielny S, et al. (2004) The poor responsiveness of infiltrating lobular breast carcinomas to neoadjuvan chemotherapy can be explained by their biological profile. Eur J Cancer 40: 342-351. [Crossref]

46. Gianni, L., et al., (2011) Treatment with trastuzumab for 1 year after adjuvant chemotherapy in patients with HER2-positive early breast cancer: a 4-year follow-up of a randomised controlled trial. Lancet Oncol 12: 236-244. [Crossref]

47. Arthur LM, Turnbull AK, Webber VL, Larionov AA, Renshaw L, et al. (2014) Molecular changes in lobular breast cancers in response to endocrine therapy. Cancer Res 74: 5371-5376. [Crossref]

48. Huang B, Omoto Y, Iwase H, Yamashita H, Toyama T, et al. (2014) Differential expression of estrogen receptor $\alpha, \beta 1$, and $\beta 2$ in lobular and ductal breast cancer. Proc Natl Acad Sci U S A 111: 1933-1938. [Crossref]

49. Riggins RB, Lan JP, Zhu Y, Klimach U, Zwart A, et al. (2008) ERRgamma mediates tamoxifen resistance in novel models of invasive lobular breast cancer. Cancer Res 68 : 8908-8917. [Crossref]

50. Sikora MJ1, Cooper KL, Bahreini A, Luthra S, Wang G, et al. (2014) Invasive lobular carcinoma cell lines are characterized by unique estrogen-mediated gene expression patterns and altered tamoxifen response. Cancer Res 74: 1463-1474. [Crossref]

51. Takagi M, Miki Y, Miyashita M, Hata S, Yoda T, et al. (2016) Intratumoral estrogen production and actions in luminal A type invasive lobular and ductal carcinomas. Breast Cancer Res Treat 156: 45-55. [Crossref]

52. Metzger Filho O, Giobbie-Hurder A, Mallon E, Gusterson B, Viale G, et al. (2015) Relative Effectiveness of Letrozole Compared With Tamoxifen for Patients With Lobular Carcinoma in the BIG 1-98 Trial. J Clin Oncol 33: 2772-2779. [Crossref]

53. Knauer M, Gruber C, Dietze O, Greil R, Stoger H, et al. (2015) Survival advantage of anastrozole compared to tamoxifen for lobular breast cancer in the ABCSG-8 study. Cancer Res 75: S2-06.

54. Metzger Filho O, Giobbie-Hurder A, Mallon E, Gusterson B, Viale G, et al. (2013)
Relative effectiveness of letrozole alone or in sequence with tamoxifen for patients diagnosed with invasive lobular carcinoma. J Clin Oncol 31: 529. [Crossref]

55. Toikkanen S, Pylkkänen L, Joensuu H (1997) Invasive lobular carcinoma of the breast has better short- and long-term survival than invasive ductal carcinoma. $\mathrm{BrJ}$ Cancer 76: 1234-1240. [Crossref]

56. Lim ST, Yu JH, Park HK, Moon BI, Ko BK, et al. (2014) A comparison of the clinical outcomes of patients with invasive lobular carcinoma and invasive ductal carcinoma of the breast according to molecular subtype in a Korean population. World J Surg Oncol 12: 56 .

57. Garcia-Fernandez, A., et al., (2015) Comparative Long-term Study of a Large Series of Patients with Invasive Ductal Carcinoma and Invasive Lobular Carcinoma. LocoRegional Recurrence, Metastasis, and Survival. Breast J 21: 533-537. [Crossref]

58. Adachi Y, Ishiguro J, Kotani H, Hisada T, Ichikawa M, et al. (2016) Comparison of clinical outcomes between luminal invasive ductal carcinoma and luminal invasive lobular carcinoma. BMC Cancer 16: 248. [Crossref]

59. Pestalozzi, B.C., et al., (2008) Distinct clinical and prognostic features of infiltrating lobular carcinoma of the breast: combined results of 15 International Breast Cancer Study Group clinical trials. J Clin Oncol 26: 3006-3014. [Crossref]

60. Korhonen T, Kuukasjärvi T, Huhtala H, Alarmo EL, Holli K, et al. (2013) The impact of lobular and ductal breast cancer histology on the metastatic behavior and long term survival of breast cancer patients. Breast 22: 1119-1124. [Crossref]

61. Lee JH, Park S, Park HS, Park BW. (2010) Clinicopathological features of infiltrating lobular carcinomas comparing with infiltrating ductal carcinomas: a case control study. World J Surg Oncol 8: 34. [Crossref]

62. El-Hage A, Ruel C, Afif W, Wissanji H, Hogue JC, et al. (2016) Metastatic pattern of invasive lobular carcinoma of the breast-Emphasis on gastric metastases. $J$ Surg Oncol 114: 543-547. [Crossref]

63. Sugimoto S, Komatsu H, Morohoshi Y, Kanai T (2015) Recognition of and recent issues in hereditary diffuse gastric cancer. $J$ Gastroenterol 50: 831-843. [Crossref]

Copyright: (C2016 Xin LJJ. This is an open-access article distributed under the terms of the Creative Commons Attribution License, which permits unrestricted use, distribution, and reproduction in any medium, provided the original author and source are credited. 